This item was submitted to Loughborough's Research Repository by the author.

Items in Figshare are protected by copyright, with all rights reserved, unless otherwise indicated.

\title{
A neural-network-like catalyst structure for the oxygen reduction reaction: carbon nanotube bridged hollow PtCo alloy nanoparticles in a MOF-like matrix for energy technologies
}

\section{PLEASE CITE THE PUBLISHED VERSION}

\section{PUBLISHER}

Royal Society of Chemistry (RSC)

\section{VERSION}

AM (Accepted Manuscript)

\section{PUBLISHER STATEMENT}

This paper was accepted for publication in the journal Journal of Materials Chemistry A and the definitive published version is available at https://doi.org/10.1039/c9ta06712d.

\section{LICENCE}

CC BY-NC-ND 4.0

\section{REPOSITORY RECORD}

Wang, Jian, Guangping Wu, Wanglan Wang, Wenhui Xuan, Jingxia Jiang, Jianchuan Wang, Li Li, Wen-Feng Lin, Wei Ding, and Zidong Wei. 2019. "A Neural-network-like Catalyst Structure for the Oxygen Reduction Reaction: Carbon Nanotube Bridged Hollow Ptco Alloy Nanoparticles in a Mof-like Matrix for Energy Technologies". figshare. https://hdl.handle.net/2134/9717587.v1. 


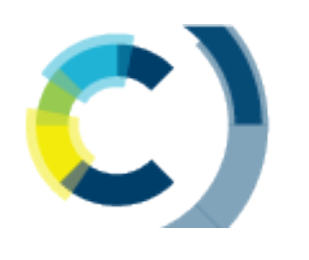

\section{Journal of \\ Materials Chemistry A}

\section{A neural-network-like catalyst structure for oxygen reduction reaction: carbon nanotubes bridged hollow PtCo alloy nanoparticles in MOF-like matrix for energy technologies}

\begin{tabular}{|r|l|}
\hline Journal: & Journal of Materials Chemistry A \\
\hline Manuscript ID & TA-ART-06-2019-006712.R1 \\
\hline Article Type: & Paper \\
\hline Date Submitted by the & $30-$ Jul-2019 \\
\hline Complete List of Authors: & $\begin{array}{l}\text { Wang, Jian; Chongqing University, School of Chemistry and Chemical } \\
\text { Engineering } \\
\text { Wu, Guangping; North University of China, School of Chemical } \\
\text { Engineering and Technology, North University of China } \\
\text { Wang, Wanglan; Chongqing University } \\
\text { Xuan, Wenhui; Chongqing University } \\
\text { jiang, jinxia; Chongqing University } \\
\text { Wang, Jianchuan; Chongqing University, School of Chemistry and } \\
\text { Chemical Engeering } \\
\text { Li, Li; Chongqing University, } \\
\text { Lin, Wen-Feng; Loughborough University, } \\
\text { Ding, Wei; Chongqing University, School of Chemistry and Chemical } \\
\text { Engineering } \\
\text { Wei, Zidong; Chongqing university, chemistry }\end{array}$ \\
\hline
\end{tabular}

\section{SCHOLARONE ${ }^{\text {TH }}$ Manuscripts}


Received 00th January 20xx, Accepted 00th January 20xx

DOI: $10.1039 / \times 0 x \times 00000 x$

\title{
A neural-network-like catalyst structure for oxygen reduction reaction: carbon nanotubes bridged hollow PtCo alloy nanoparticles in MOF-like matrix for energy technologies
}

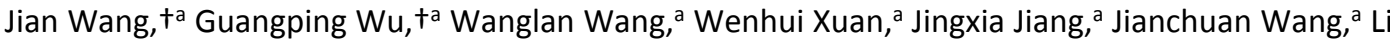

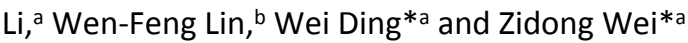

\begin{abstract}
The rational design of catalytic layer in the membrane-electrode assembly is the key to achieve high performances from proton exchange membrane fuel cells (PEMFCS). Herein, inspired by neural-network structure of brain, we constructed a bionic catalytic network for oxygen reduction reaction (ORR), via setting up Pt-organic ligands-Co ${ }^{2+}$-organic ligands-Pt connections and then thermally transforming them into a metal-organic-framework (MOF)-like matrix in which hollow PtCo alloy nanoparticles (NPs) with anverage particle size of $4.4 \mathrm{~nm}$ are bridged together by carbon nanotubes (PtCo@CNTsMOF). The bionic catalytic network endows highly efficient linkages of various species-transport channels to active sites; as a result, an order of magnitude improvement is achieved in mass transfer efficiency as compared to the traditional Pt/C catalytic layer. Besides, the hollow PtCo alloy derived from Pt NPs shows a high initial mass activity of $852 \mathrm{~mA} \mathrm{mgPt}^{-1} @ 0.90$ $\checkmark$ and an undetectable decay in an accelerate aged test. Accordingly, a remarkable Pt utilization efficiency of $58 \mathrm{mgPt} \mathrm{kW}^{-1}$ in fuel cell cathode and $98 \mathrm{mgPt} \mathrm{kW}^{-1}$ in both anode and cathode, were eventually achieved, respectively. The latter is almost 3 times higher than that from the traditional catalytic layer. Moreover, no decay was detected during continuous operation at $1 \mathrm{~A} \mathrm{~cm}^{-2}$ for 130 hours from the bionic catalytic network based fuel cell. This strategy offers a new concept for designing ultra-low Pt loading yet highly active and durable catalytic layer for fuel cell applications and beyond.
\end{abstract}

\section{Introduction}

The key issues that impede the widespread commercialization of automotive proton exchange membrane fuel cells (PEMFCs) are the cost and durability. ${ }^{1-4}$ Currently the cost of PEMFCs system is valued to be about $45 \$$ per $\mathrm{kW}$, and the platinumbased catalyst, as the state-of-the-art for the oxygen reduction reaction (ORR) in the PEMFC, contributes most to the entire cost of PEMFCs. ${ }^{5-11}$ Thus, intensive efforts have been made in developing highly active platinum-based catalysts to ensure high ORR kinetics. Significant progresses have been achieved by rational design of the catalysts in terms of composition, structure and even single Pt atom dispersed nanocatalysts. ${ }^{2,12-}$ 16 Nonetheless, their applications in PEMFCs still face great challenges in Pt utilization and durability, especially at extremely low metal loadings $\left(<0.125 \mathrm{mg} \mathrm{cm}^{-2} \mathrm{Pt}\right.$ on two electrodes).

The catalytic layer in the membrane-electrode assembly (MEA) is of great importance to the cell performance. ${ }^{17}$ It is not only responsible for the electrochemical reaction/energy conversion but also guarantees the high-speed mass transport. The conventional catalytic layer structure is a random stack of catalyst particles, usually $30 \sim 50 \mathrm{~nm}$ carbon particles banded with each other by ionomers. The random distributed catalytic layer brings lots of narrow channels and dead ends for gas transportation, leading to inefficient mass transport and low Pt utilization. Consequently, the super-high activity of the developed Pt catalyst can hardly be realized in the real fuel cell. For instance, the recent developed Pt-Ni nanoframes that exhibited extremely high mass activity of $5.7 \mathrm{~A} / \mathrm{mgPt}$ in a liquid halfcell for ORR only showed about one-tenth of activity in a real cell $(0.76 \mathrm{~A} / \mathrm{mg}$ Pt at $0.90 \mathrm{~V}) .{ }^{12}$ To this end, the traditional, random stack of catalyst layer fails in providing highly efficient linkage of various species-transport channels to active sites for high performance catalysts.

As inspired by nature, solutions for solving this problem can be provided from a brain neural system. As shown in scheme 1, about twelve billion neural cells are connected with each other, and every single one can work efficiently. This is because brain system has the most efficient linkage in its network, where neural cells connected with each other by a thin and long protoplasmic fiber, and isolated from each other by glia as well, ${ }^{18}$ which guarantees efficient cell connections and channels in the neural network.

Learned from the sophisticated brain neural system, a bionic PtCo NPs network connected with carbon nanotubes (CNTs) support was successfully developed in this work to improve the overall $\mathrm{Pt}$ utilization in fuel cell cathode reaction. This method relies on in-situ transformation of Pt-organic ligands- $\mathrm{Co}^{2+}$-organic ligands-Pt connections within metal organic framework (MOF). As shown in scheme 1, the polyvinyl pyrrolidone (PVP) and 2-methyl imidazole (DMIM) capped Pt NPs were used as "center species", and connected with each other by adding $\mathrm{Co}^{2+}$ ions to form Pt-organic ligands- $\mathrm{Co}^{2+}$ organic ligands-Pt connections. Such connections then grew into zeolitic framework crystals (donated as Pt@ZIF-67). After controlled pyrolysis at low heating rate of $1^{\circ} \mathrm{C} \mathrm{min}^{-1}$, these connections were converted into MOF-like CNTs aggregate under a mixture gas flow of

\footnotetext{
a. Chongqing Key Laboratory of Chemical Process for Clean Energy and Resource Utilization, School of Chemistry and Chemical Engineering, Chongqing University, Shapingba 174, Chongqing, China

b. Department of Chemical Engineering, School of AACME, Loughborough

University, Loughborough, Leicestershire, LE11 3TU, U.K.

+ These authors contributed equally.

Electronic Supplementary Information (ESI) available: [details of any supplementary information available should be included here]. See DOI: 10.1039/x0xx00000x
} 


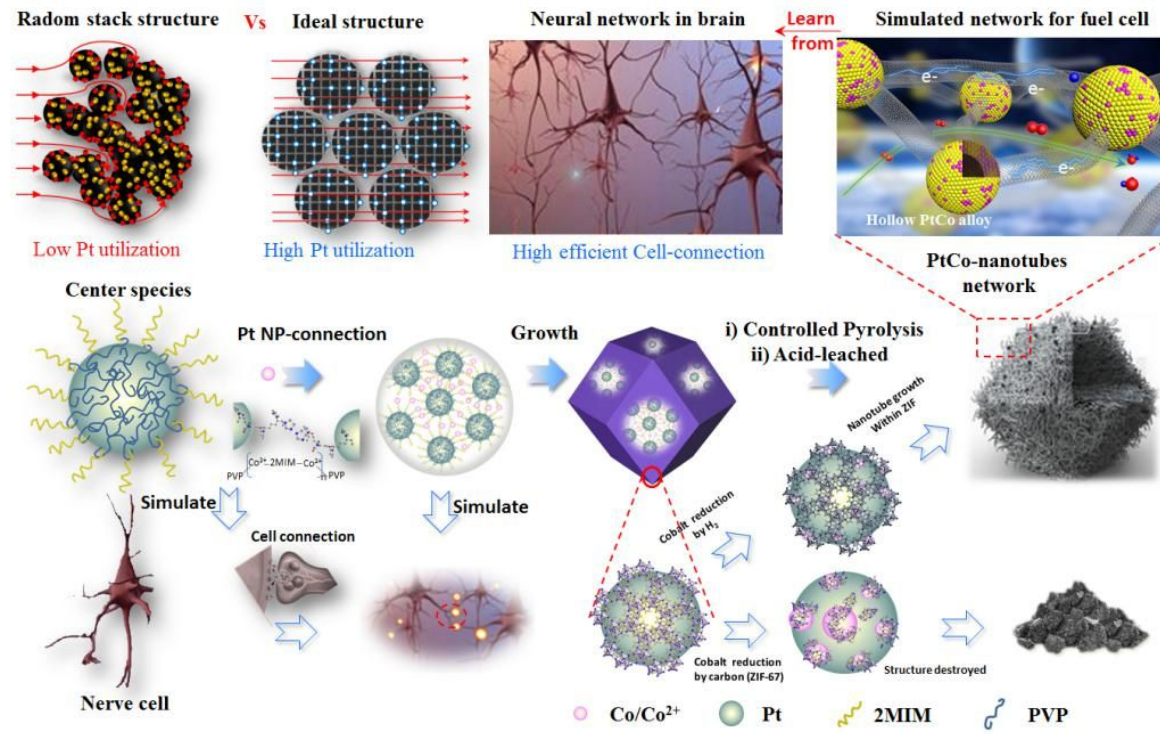

Scheme 1. Schematic illustration of the bionic design of hollow alloy catalyst, inspired by nature (brain neural network).

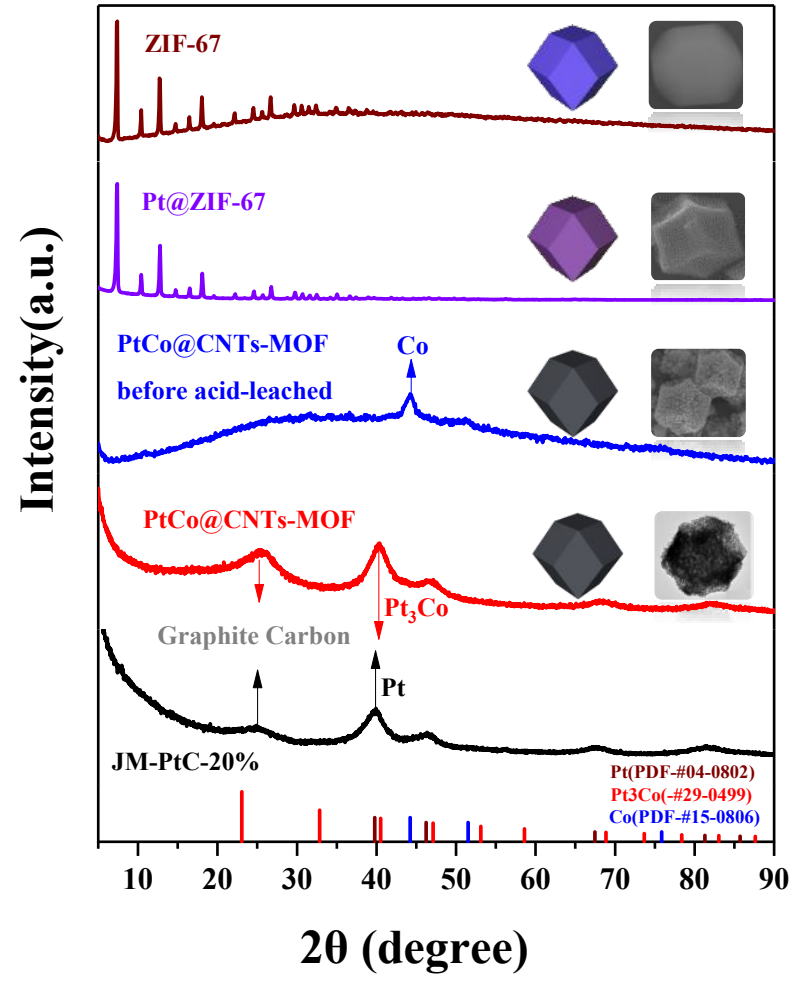

Figure 1. The XRD patterns of the samples during the fabrication of PtCo@CNTs-MOF catalyst. Brown curve: pure ZIF-67, purple curve: Pt NPs embedded ZIF-67 (Pt@ZIF-67), blue curve: Pt@ZIF-67 after controlled pyrolysis (PtCo@CNTs-MOF), red curve: PtCo@CNTs-MOF after acid-leached, black curve: commercial Pt/C.

hydrogen and nitrogen (supporting information for experimental details). The Pt NPs, on the other hand, were transformed into hollow PtCo alloy NPs and connected by CNTs within the aggregate (donated as PtCo@CNTs-MOF). As for comparison, the PtCo/C catalyst produced by traditional pyrolysis of Pt@ZIF-67 at relatively high heating rate of $5{ }^{\circ} \mathrm{C} \mathrm{min}-1$ and Co@CNTs-MOF catalyst produced by the same controlled pyrolysis of ZIF-67 were obtained, respectively (figure $\mathrm{S} 1$ for experimental details). The as-prepared catalytic network exhibits bionic features that showing the center active sites connected with but isolated from each other, and thus, the whole network provides enough space for mass transport and Pt utilization. As a result, an order of magnitude improvement in mass transfer efficiency was achieved as compared to the traditional $\mathrm{Pt} / \mathrm{C}$ or $\mathrm{PtCo} / \mathrm{C}$ catalytic layer, according to the mass transfer-determined experiment. And the PtCo alloy NPs also exhibited significantly enhanced initial mass activity $\left(852 \mathrm{~mA} \mathrm{mg \textrm {Pt } ^ { - 1 }}\right.$ at $0.90 \mathrm{~V}$ vs reversible hydrogen electrode, RHE) and even better aged/long term mass activity (880 mA mg ${ }_{\mathrm{pt}^{-1}}$ ) after subjected to 10000 accelerate aging cycles, which is 4.8 and 5.0 times higher than that obtained from commercial Pt/C catalyst, respectively. Consequently, the fuel cell/ MEA employing the bionic catalytic network catalyst achieved a maximum power density up to $1.02 \mathrm{~W} \mathrm{~cm}^{-2}$ at an ultra-low Pt loading of only $60 \mu \mathrm{g} \mathrm{cm}{ }^{-2}$ in the cathode. The corresponding Pt utilization efficiency reached a remarkable high level of $58 \mathrm{mg} \mathrm{Pt} \mathrm{kW}^{-1}$ with regard to cathode side, and $98 \mathrm{mgPt} \mathrm{kW}^{-1}$ counting both anode and cathode sides together, the latter is 3 times better than that from the traditional Pt/C catalytic layer.

\section{Results and discussion}

\section{Structural characterization of the materials synthesized}

The X-ray diffraction (XRD) and nitrogen adsorption desorption isotherms were adopted to monitor the synthetic materials in each step. As shown in figure 1, a well-defined XRD pattern of zeolitic framework crystalline structure was observed for the as-synthesized Pt@ZIF-67, demonstrating a well maintained ZIF-67 structure after center Pt NPs connected together within its crystalline. In addition, the Brunauer-Emmet-Teller (BET) specific surface area and pore size distribution of Pt@ZIF-67 (1121 $\left.\mathrm{m}^{2} \mathrm{~g}^{-1}\right)$ were both similar to those of pure ZIF-67 (1373 $\left.\mathrm{m}^{2} \mathrm{~g}^{-1}\right)$, further implying a similar pore structure after Pt NPs being connected (figure S2). After the pyrolysis, only one peak around $44^{\circ}$ attributing to metallic Co was left for PtCo@CNTsMOF catalyst (figure 1), and the BET surface area decreased to 146 $\mathrm{m}^{2} \mathrm{~g}^{-1}$ (figure S2). This is due to that the reduced Co atoms at high temperature aggregated to lager Co particles (the inset image in figure 1), leading to severe blocking of pores.

After being acid-leached, an intermetallic $\mathrm{Pt}_{3} \mathrm{Co}$ crystal structure with diffraction peaks at $40^{\circ}, 47^{\circ}, 68^{\circ}$ and $83^{\circ}$ was observed, indicating a certain of Co atoms diffused into the encapsulated Pt NPs to form PtCo alloy during the pyrolysis. Similarly, the diffusion of Co atoms also occurred in traditional pyrolysis of Pt@ZIF-67 at relatively high heating rate of $5^{\circ} \mathrm{C} \mathrm{min}^{-1}$ and in the controlled pyrolysis of ZIF67 at low heating rate of $1^{\circ} \mathrm{C} \mathrm{min}-1$, which leads to the formation of $\mathrm{Pt}_{3} \mathrm{Co}$ and $\mathrm{Co}_{2} \mathrm{~N}$ structures in the PtCo/C and Co@CNTs-MOF catalysts, respectively (figure S3). Different from the previous reports where they used an excessive Co doped MOF as supplier to synthesize PtCo alloy, 14, 19, 20 we show that the Pt NPs can be efficiently transformed into intermetallic $\mathrm{Pt}_{3} \mathrm{Co}$ by confined within 


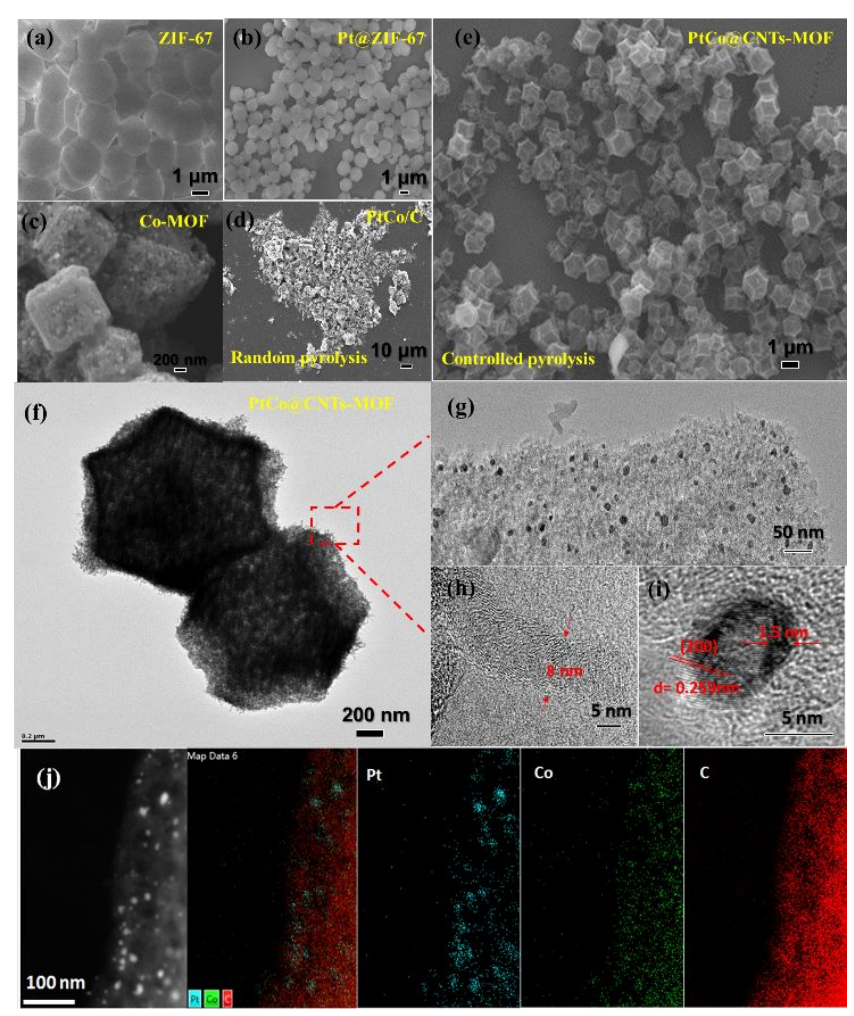

Figure 2. (a) The SEM image of ZIF-67, (b) the SEM image of Pt@ZIF-67, (c) the SEM image of the Co@CNTs-MOF after controlled pyrolysis process of ZIF-67, (d) the SEM image of the PtCo/C after random pyrolysis process of Pt@ZIF-67, (e) the SEM image of the PtCo@CNTs-MOF after controlled pyrolysis process of Pt@ZIF-67, (f,g,h,i) the TEM images of PtCo@CNTs-MOF, (j) the elemental mappings of PtCo@CNTs-MOF.

MOF structure. Meanwhile, the organic ligands of ZIF-67 were transformed into carbon materials with graphite (002) diffraction peak around $25^{\circ}$. The BET surface area of the PtCo@CNTs-MOF increased to $455 \mathrm{~m}^{2} \mathrm{~g}^{-1}$ after the acid-leaching process, which is almost the same as that of carbonized pure ZIF-67 (Table S1). In contrast, the $\mathrm{PtCo} / \mathrm{C}$ exhibited a relative low BET surface area (355 $\left.\mathrm{m}^{2} \mathrm{~g}^{-1}\right)$ with a larger size $(6.8 \mathrm{~nm})$ as produced by traditional random pyrolysis than that of PtCo@CNTs-MOF. (Table S1 and figure S4a, figure S1d).

The scanning electron microscopy (SEM) images demonstrated the well-maintained polyhedral morphology after Pt NPs being induced into the crystals (figure $2 \mathrm{a}$ and $\mathrm{b}$ ). During the controlled pyrolysis (figure S1a) at a low heating rate $\left(1{ }^{\circ} \mathrm{C} \mathrm{min}^{-1}\right)$, the $\mathrm{Co}^{2+}$ species were selectively reduced by $\mathrm{H}_{2}$, and thus the polyhedral morphology could be preserved effectively for PtCo@CNTs-MOF (Fig. $2 \mathrm{a}-\mathrm{c}$ and e, figure S4b). However, for $\mathrm{PtCo} / \mathrm{C}$, the $\mathrm{Co}^{2+}$ species were reduced by organic ligands of ZIF-67 rather than $\mathrm{H}_{2}$ under random pyrolysis (figure $\mathrm{S} 1 \mathrm{~b}$, ), resulting in an uncontrollable collapse in morphology (figure 2d, figure $54 \mathrm{c}$ ). According to the high-resolution transmission electron microscopy (HRTEM) images, the final catalysts exhibited a porous MOF-like structure, which consisted of interconnected CNTs with a diameter of $8 \mathrm{~nm}$ and hollow $\mathrm{Pt}_{3}$ Co NPs with a wall thickness of $1.5 \mathrm{~nm}$ (figure $2 \mathrm{f}-\mathrm{i}$ ). It was noticed that the CNTs directly grew out of the surface of PtCo NPs (figure S5) to form PtCo-nanotube connections as depicted in scheme 1. This was attributed to the diffusion of pre-reduced Co atoms into Pt NPs which then catalysed the in-situ growth of CNTs. We believe that the preferential $\mathrm{H}_{2}$-reduction of isolated $\mathrm{Co}^{2+}$ species over the reduction of them by organic ligands of ZIF-67 in the low heating rate pyrolysis is the main reason for the well-maintained MOF-like morphology. We carried out the $\mathrm{H}_{2}$ temperature program reduction ( $\mathrm{H}_{2}$-TPR) to verity this speculation. As shown in figure $\mathrm{S} 1 \mathrm{c}, \mathrm{H}_{2}$-TPR profile with heating rate of $1^{\circ} \mathrm{C} \mathrm{min}-1$ exhibited three distinct reduction peaks at 280,390, and $490{ }^{\circ} \mathrm{C}$, respectively, which are attributed to the reduction of $\mathrm{Co}^{2+}$ near Pt NPs, ${ }^{21}$ reduction of isolated $\mathrm{Co}^{2+}$ in $\mathrm{ZIF}-67,{ }^{21}$ and gasification of carbon..$^{22}$ When the heating rate was increased to $5^{\circ} \mathrm{C}$ $\mathrm{min}^{-1}$, however, the peak assigning to the reduction of isolated $\mathrm{Co}^{2+}$ in ZIF-67 almost disappeared, indicating that most of the isolated $\mathrm{Co}^{2+}$ in ZIF-67 were not react with $\mathrm{H}_{2}$ anymore. According to the XRD results, all $\mathrm{Co}^{2+}$ species were reduced after pyrolysis. Therefore, the isolated $\mathrm{Co}^{2+}$ ions would be reduced by organic ligands of MOF at heating rate of $5{ }^{\circ} \mathrm{C} \mathrm{min}^{-1}$, leading to a much lower $\mathrm{H}_{2}$ consumption at the same precursor feeding ( $0.3 \mathrm{~g})$ (figure S1c). These results, in combination with the TEM/SEM and XRD data, demonstrate that the preferential $\mathrm{H}_{2}$-reduction of $\mathrm{CO}^{2+}$ species in ZIF-67 protected the organic ligands of MOF from being destroyed by reduction of $\mathrm{Co}^{2+}$ species at the low heating rate pyrolysis, which in turn creates the chance to transform organic ligands into carbon nanotube under the catalysis of Co metals during the pyrolysis. EDX elemental mapping and HADDF images (figure $2 \mathrm{j}$ ) revealed a uniform atomic dispersion of $\mathrm{Co}$ and $\mathrm{C}$ in the porous MOF-like hollow structure, indicating the formation of Co-N-C sites which may act as the second active site for ORR. X-ray photoelectron
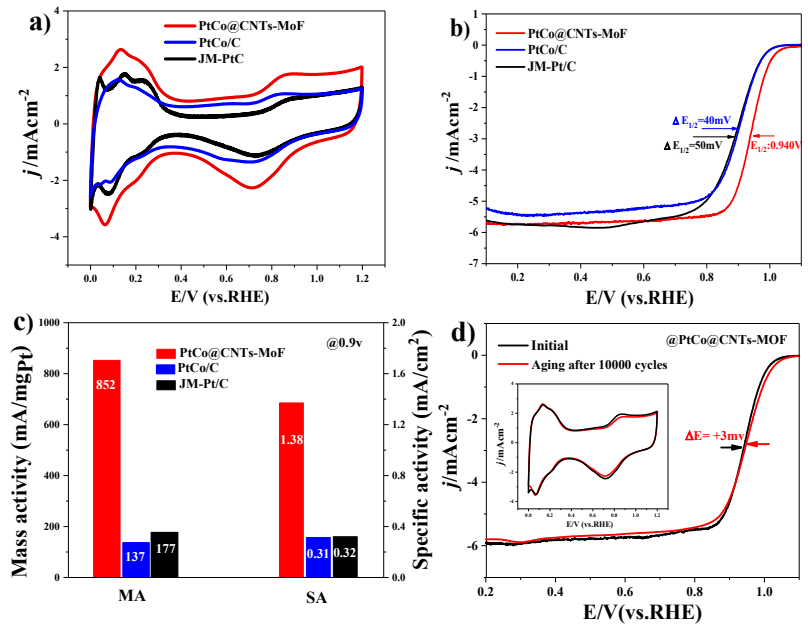

Figure 3. (a) CV curves of PtCo@CNTs-MOF and commercial Pt/C recorded in $\mathrm{N}_{2}$-purged $0.1 \mathrm{M} \mathrm{HClO}_{4}$ solution at a scanning rate of $50 \mathrm{mV} \mathrm{s}^{-1}$; (b) ORR polarization curves of PtCo@CNTs-MOF and commercial Pt/C recorded in $\mathrm{O}_{2}$-saturated $0.1 \mathrm{M} \mathrm{HClO}_{4}$ solution at room temperature; (c) Mass activity and specific activity of PtCo@CNTs-MOF, PtCo/C and commercial Pt/C at 0.90V vs RHE; (d) The LSV curves of PtCo@CNTs-MOF before and after 10000 cycles at a rotating speed of $1600 \mathrm{rpm}$ in an 02 -saturated $0.1 \mathrm{M} \mathrm{HClO}_{4}$ solution with a sweep rate of $50 \mathrm{mV} \mathrm{s}^{-1}$. The inset picture is the CV curves of PtCo@CNTsMOF before and after 10000 cycles recorded in $\mathrm{N}_{2}$-purged $0.1 \mathrm{M} \mathrm{HClO}_{4}$ solution at a scanning rate of $50 \mathrm{mV} \mathrm{s}^{-1}$.

spectroscopy (XPS) also identified the existence of Co-Nx (399.6 eV) sites in PtCo@CNTs-MOF (figure S6).

\section{Reactivity of the bionic catalyst towards ORR}

The electrocatalytic reactivities of the as-prepared bionic catalytic network were examined in an $\mathrm{O}_{2}$ or $\mathrm{N}_{2}$-saturated $0.1 \mathrm{M} \mathrm{HClO}_{4}$ solution. As shown in figure 3a, the PtCo@CNTs-MOF modified electrode exhibited a relative larger double capacitance than that of the commercial $\mathrm{Pt} / \mathrm{C}$ modified electrode, indicating a larger solidliquid interface area of the as-prepared bionic catalytic network. Cyclic voltammograms (CVs) with different scanning rates showed 4times larger double layer capacitance per mass and 1.2-times larger per BET surface area for PtCo@CNTs-MOF than those for commercial 


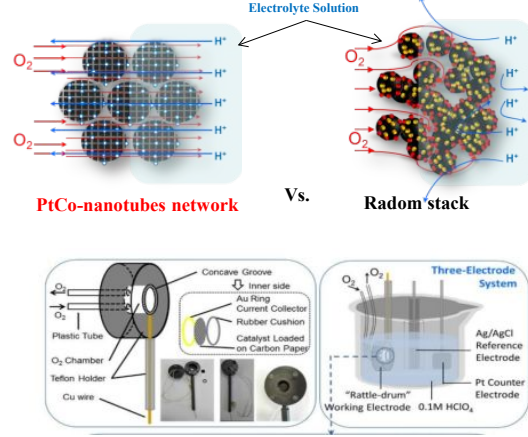

The self-made "rattle-drum"-like working electrode
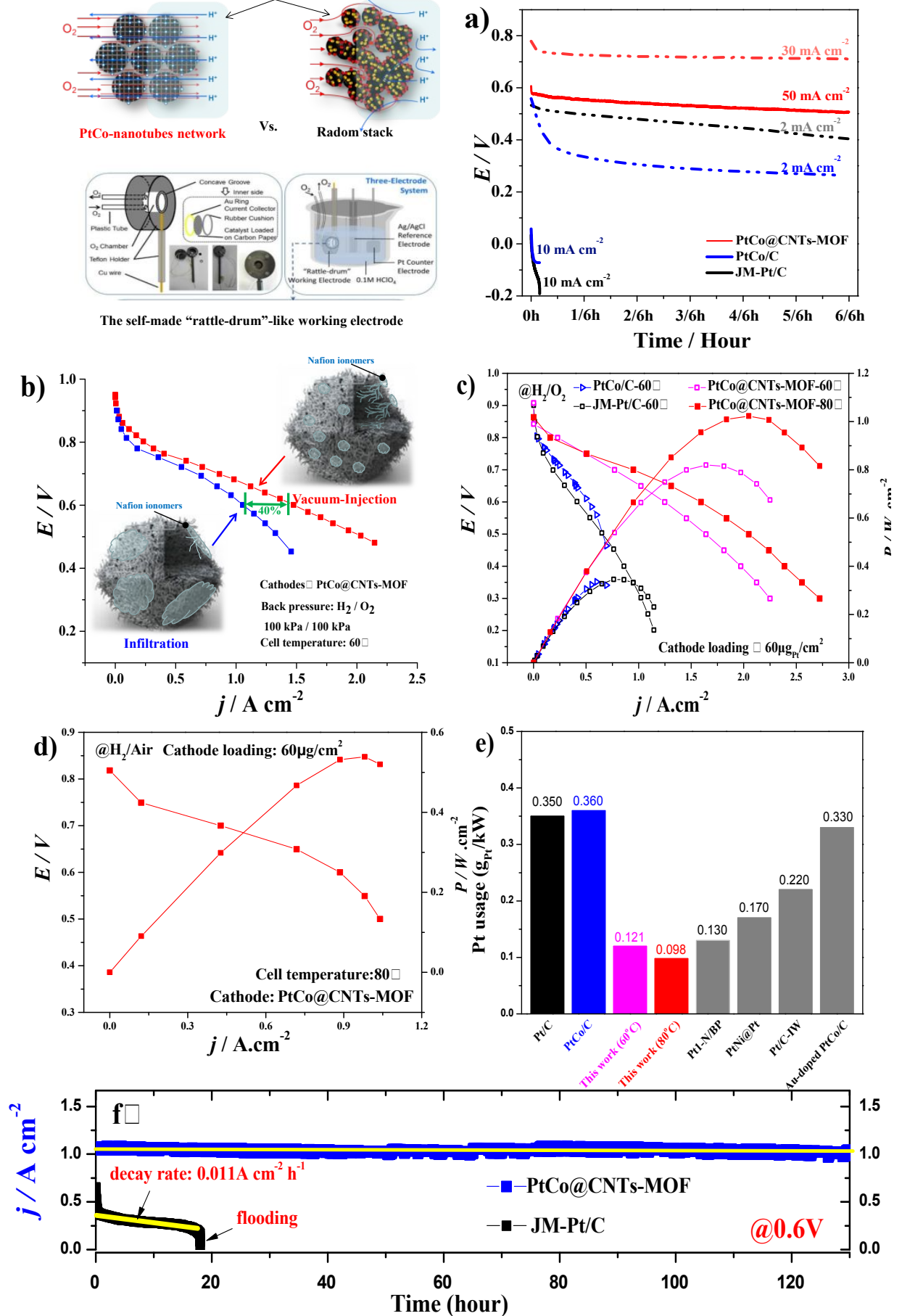

Figure 4. a) The chronopotentiometry curves of PtCo@CNTs-MOF, PtCo/C and the commercial Pt/C with Pt loading of $0.025 \mathrm{mg} \mathrm{cm}^{-2}$. The data were obtained in the three- electrode testing system constructed by a "rattle-drum" working electrode, a carbon rob counter electrode and a $\mathrm{Ag} / \mathrm{AgCl}$ reference electrode. $\mathrm{b}) \mathrm{I}-\mathrm{V}$ polarization curves of the MEAs in a single $\mathrm{H}_{2} / \mathrm{O}_{2}$ fuel cell employing the PtCo@CNTs-MOF cathode with different treatment of vacuuminjection or infiltration at $60{ }^{\circ} \mathrm{C}$. c) The voltages and power densities of the $\mathrm{H}_{2} / \mathrm{O}_{2}$ fuel cell employing PtCo@CNTs$\mathrm{MOF}, \mathrm{PtCo} / \mathrm{C}$ and commercial Pt/C, respectively, as the cathode with $60 \mu \mathrm{g} \mathrm{Pt} \mathrm{cm}{ }^{-2}$ loading; JM-PtRu/C was used as the anode with 40, 60 and $60 \mu \mathrm{g} \mathrm{Pt} \mathrm{cm}{ }^{-2}$ loading, respectively; the membrane used was Nafion-HP; data obtained at 60 and $80^{\circ} \mathrm{C}$. d) The voltages and power densities of the $\mathrm{H}_{2} /$ Air fuel cell with PtCo@CNTs-MOF cathode $(60 \mu \mathrm{g} \mathrm{Pt} \mathrm{cm}-$ ${ }^{2}$ ), JM-PtRu/C anode $\left(40 \mu \mathrm{g} \mathrm{Pt} \mathrm{cm}{ }^{-2}\right)$ at $80{ }^{\circ} \mathrm{C}$. e) Comparison of the Pt usage of JM-Pt/C, PtCo/C, PtCo@CNTs-MOF, Pt1-N/BP, ${ }^{26}$ PtNi@Pt, ${ }^{27}$ Au-doped PtCo/C ${ }^{28}$ and Pt/C-IW 29 in MEA/whole cell with the peak power density achieved. f) Comparison of the fuel cell lifetime test at $0.60 \mathrm{~V}$ over $130 \mathrm{~h}$ for the MEAs employing PtCo@CNTs-MOF and JM$\mathrm{Pt} / \mathrm{C}$ as the cathode, respectively.

$\mathrm{Pt} / \mathrm{C}$ (figure S7), implying a higher efficiency in producing active interface of the bionic catalytic network. Figure $3 b$ showed the evaluation of electrocatalytic activities of the as-prepared catalysts towards ORR in an $\mathrm{O}_{2}$ saturated $0.1 \mathrm{M}$ $\mathrm{HClO}_{4}$ solution. The ORR polarization curve of PtCo@CNTs-MOF catalyst showed a more positive half-wave potential $(0.94 \mathrm{~V})$ than those of commercial Pt/C (0.89V) and Co-MOF (0.41V) (figure $3 \mathrm{~b}$ and figure S8). The corresponding mass activity of PtCo@CNTs-MOF reached a relatively high level of $852 \mathrm{~mA} \mathrm{mg}_{\mathrm{Pt}}^{-1}$ at $0.90 \mathrm{~V}$ vs RHE, which was 4.8 times higher than that of the commercial $\mathrm{Pt} / \mathrm{C}$ catalyst. In contrast, the random pyrolyzed $\mathrm{PtCo} / \mathrm{C}$ catalysts only possessed a mass activity of $137 \mathrm{~mA}$ $\mathrm{mg}_{\mathrm{Pt}^{-1}}$ at $0.90 \mathrm{~V}$ vs RHE. As these evaluations were conducted in a solution electrolyte, there is only a tiny difference in Pt utilization for the produced catalyst. The enhanced activity of PtCo@CNTs-MOF can only be attributed to the formation of hollow PtCo alloy structure. In addition, the electrochemical surface areas (ECSA) of PtCo@CNTs-MOF, $\mathrm{PtCo} / \mathrm{C}$ and $\mathrm{Pt} / \mathrm{C}$ were evaluated to be 62,43 and $55 \mathrm{~m}^{2} \mathrm{gPt}^{-1}$, respectively (figure S9a), and the corresponding specific activities were determined to be 1.38, 0.31, and $0.32 \mathrm{~mA} \mathrm{~cm}{ }^{-2}$, respectively (figure $3 \mathrm{c}$ ). The high specific activity of PtCo@CNTs-MOF also suggested a high intrinsic ORR activity of the PtCo hollow structure.

The electrochemical durability of the PtCo@CNTs-MOF catalyst was evaluated by accelerate decay test (ADT) at potential sweeping between 0.60 and $1.10 \mathrm{~V} v$ v RHE in $0.1 \mathrm{M} \mathrm{HClO}_{4}$ solution, and compared to the commercial Pt/C. An obvious degradation for the commercial Pt/C catalyst with regards to both the electrochemical surface area and the reactivity towards ORR, was observed, the latter having the half-current peak potential $\left(E_{1 / 2}\right)$ negatively shifted for $40 \mathrm{mV}$ (figure S10). However, to one's surprise, the PtCo@CNTs-MOF catalyst showed a positive shift of 3 $\mathrm{mV}$ in $E_{1 / 2}$ after 10000 cycles, with a mass activity increase of $3.3 \%$ simultaneously (figure 3d). This phenomenon could be explained by the formation of more stable PtCo alloy structure with the certain of $\mathrm{Co}$ atoms de-alloyed from PtCo alloy. ${ }^{23}$ According to the previous results, both high anti-oxidation of $\mathrm{Pt}$ and strong NPs-support interaction can benefit for the stability of Pt- 
based catalysts during ORR. ${ }^{24}$ In this work, the PtCo@CNTs-MOF and $\mathrm{PtCo} / \mathrm{C}$ exhibited significant higher anti-oxidation than commercial $\mathrm{Pt} / \mathrm{C}$ with a CO stripping potential lag by $\sim 90 \mathrm{mV}$ (figure S9b)..$^{25}$ The negatively shifted binding energy of $\mathrm{Pt}$ as compared with that of commercial Pt/C further suggests a strong NPs-support interaction and electron transfer between Co and Pt atoms (figure S11). Therefore, the designed catalysts displayed an amazing electrochemical durability.

To verify the superiority of the PtCo-nanotubes connected catalytic network in mass transfer, a mass transfer-determined experiment in a complete water flooding situation was carried out (see supporting information for details). As shown in figure 4a, after the catalyst modified gas-diffusion electrode (GDE) was fully immersed into $0.1 \mathrm{M} \mathrm{HClO}_{4}$ solution, the reactive $\mathrm{O}_{2}$ gas was then blew into the GDE from the back side to initiate the reaction. Since the pores of GDE were filled with electrolyte which provided sufficient protons during ORR, the cathodic current thus only depended on the mass transfer capability of catalytic layers. For the traditional GDEs fabricated with $\mathrm{Pt} / \mathrm{C}$ and $\mathrm{PtCo} / \mathrm{C}$ random stacked catalytic layer, the steady current only reached as low as $2 \mathrm{~mA} \mathrm{~cm}{ }^{-2}$ at $0.30 \mathrm{~V}$. Further increasing the current to $10 \mathrm{~mA} \mathrm{~cm}^{-2}$, the cathode potential rapidly dropped to below $0 \mathrm{~V}$, indicating that the reversed reaction of the fuel cell mode, i.e., the electrolysis of water, became the main reaction due to lacking of reactive $\mathrm{O}_{2}$ gas transfer. These results indicated that the traditional random stacked catalytic layer had totally lost its mass transfer capability under such situation. Whereas, for the PtCo@CNTs-MOF modified GDE, the cathodic current reached $50 \mathrm{~mA} \mathrm{~cm}^{-2}$ at a much higher cathode potential of $0.50 \mathrm{~V}$, which is 25 times higher than that of traditional GDE. The 25 times increase in the current density implies an order of magnitude improvement in mass transfer efficiency. This mainly contributed to the binoic design of neural network catalytic layer, in which highly efficent linkages for various species-transport channels were constructed, including voids for $\mathrm{O}_{2}$ and water, and carbon framework for electrons.

In order to construct efficient proton transfer pathway within the neural-network-like catalytic layer in real fuel cell application, the PtCo@CNTs-MOF catalyst was immersed into the sulfonated tetrafluoroethylene based fluoropolymer-copolymer (Nafion) solution and then placed into a vacuum oven to inject Nafion into the whole bionic struture. As shown in figure $4 b$, the MEA/fuel cell employing PtCo@CNTs-MOF fabricated by vacuum injection method shows an increase in the current density by $40 \%$ (at $0.60 \mathrm{~V}$ ) as compared to that using catalysts fabricated with traditional infiltration method. This indicates that the utilization of inner catalytic sites of bionic network was achieved by vacuum-injection method for boosting the performance of fuel cells.

The MEA employing PtCo@CNTs-MOF as cathode with extreme low Pt loading of $60 \mu \mathrm{g} \mathrm{pt} \mathrm{cm}^{-2}$ was further evaluated to demonstrate the advantages of the designed catalytic network. The anode Pt loading was set at $40 \mu \mathrm{g} \mathrm{pt} \mathrm{cm}^{-2}$. As shown in figure $4 \mathrm{c}$, a high performance with maximum power density of $0.82 \mathrm{~W} \mathrm{~cm}^{-2}$ was achieved at $60{ }^{\circ} \mathrm{C}$. Whereas, the MEA fabricated using $\mathrm{PtCo} / \mathrm{C}$ and commercial Pt/C catalysts could only output $0.33 \mathrm{~W} \mathrm{~cm}^{-2}$ and $0.34 \mathrm{~W}$ $\mathrm{cm}^{-2}$, respectively. For the MEA employing PtCo@CNTs-MOF cathode, when the running temperature was increased to $80^{\circ} \mathrm{C}$, the power density reached to $1.02 \mathrm{~W} \mathrm{~cm}^{-2}$. The latter indicates a high $\mathrm{Pt}$ unitization of $98 \mathrm{mg} \mathrm{pt} \mathrm{kW}^{-1}$ in the designed catalytic network, which is 3.6 times higher than that of the state of art PEMFC with the commercial $\mathrm{Pt} / \mathrm{C}$ catalyst and $\mathrm{PtCo} / \mathrm{C}$, making it among the most efficient catalysts reported to date (in figure 4d). As for the $\mathrm{H}_{2}$ /air fuel cell application, the PtCo@CNTs-MOF based MEA for the $\mathrm{H}_{2}$ /air fuel cell had also output $0.54 \mathrm{~W} \mathrm{~cm}^{-2}$ at a low Pt loading of $60 \mu \mathrm{g} \mathrm{pt}$ $\mathrm{cm}^{-2}$ at $80^{\circ} \mathrm{C}$ (figure $4 \mathrm{~d}$ ), which is in fact among the top performance reported to date. ${ }^{26-29}$ All of these results demonstrate the remarkable advantage of the designer PtCo@CNTs-MOF catalyst in Pt utilization at extreme low Pt loading catalytic layer, thanks to its unique Pt-connection, larger surface area, high speed mass transfer and excellent electrochemical active sites exposure. Furthermore, the fuel cell durability was also evaluated at fixed potential with a relatively high current density of $1 \mathrm{~A} \mathrm{~cm}^{-2}$. As shown in figure $4 \mathrm{f}$, no decay in current density was detected over a 130 hours continuous operation, indicating an excellent durability of the bionic network PtCo@CNTs-MOF catalyst. By contrast, the traditional Pt/C based MEA/fuel cell showed a serious decay rate of $0.011 \mathrm{~A} \mathrm{~cm}^{-2} \mathrm{~h}^{-1}$ and suffered from water flooding after 18 hour continuous operation under the same situation, which indicates that the traditional ultralow Pt loading catalytic layer failed to keep smooth mass transport during the fuel cell operations.

\section{Conclusions}

In summary, a neural-network-like catalytic layer via bionic design was successfully constructed, in which hollow PtCo alloy nanoparticles were connected by carbon nanotubes in a MOFlike structure. The low heating rate during the synthesis which leads to the preferential $\mathrm{H}_{2}$-reduction of $\mathrm{Co}^{2+}$ species over $\mathrm{Co}^{2+}$ reduction by organic ligands of ZIF-67, is of importance to obtain the neural-network-like structure. It benefits the following aspects: i) facilitation of the graphitization of carbon precursors and the crystallization of PtCo alloy NPs during the pyrolysis; ii) reservation of the original polyhedral MOF morphology and promotion of the growth of carbon nanotubes within the MOF-like structure; iii) increasing the exposure of PtCo NPs and enhancing the catalytic activity for ORR. Therefore, this newly designed catalytic network exhibited excellent electrocatalytic activity with mass activity of $852 \mathrm{~mA} \mathrm{mgPt}^{-1}$ and specific activity for the oxygen reduction reaction of $1.38 \mathrm{~mA}$ $\mathrm{cm}^{-2}$ at $0.90 \mathrm{~V}$ vs RHE. It also showed a remarkable electrochemical stability after being subjected to 10000 cycles accelerate durability test. Owning to its unique bionic PtCo NPsCNTs well-connected network, an order of magnitude improvement in mass transfer efficiency was achieved as compared to the traditional catalytic layer. The efficient mass transport capability of the designed catalyst network and the thermally formed hollow PtCo alloy structure led to the high performance with a high Pt utilization of $98 \mathrm{mg} \mathrm{Pt} \mathrm{kW}^{-1}$ in a real hydrogen-oxygen fuel cell operation. Also, the PtCo@CNTsMOF catalyst-based fuel cell showed an excellent durability with no decay over 130 hours continuous operation. The demonstrated catalytic strategy offers a new concept for the design of highly efficient catalytic layers for various fuel cells applications and even wider catalytic reactions for energy and environmental engineering.

\section{Conflicts of interest}

There are no conflicts of interest to declare 


\section{Acknowledgements}

This work was financially supported by International cooperation project of national natural science foundation of China (Grant Nos. 21761162015), the National Natural Science Foundation of China (Grant Nos. 21706019, 21436003, 21573029 and 21776024), the EPSRC (EP/I013229/1), the Royal Society and the Newton Fund (NAF\R1\191294).

\section{Notes and references}

1. M. W. Jianglan Shui, Feng Du, Liming Dai, Sci. Adv. , 2015, 1, e1400129.

2. X. Zeng, J. Shui, X. Liu, Q. Liu, Y. Li, J. Shang, L. Zheng and R. Yu, Advanced Energy Materials, 2018, 8.

3. L. Xue, Y. Li, X. Liu, Q. Liu, J. Shang, H. Duan, L. Dai and J. Shui, Nat Commun, 2018, 9, 3819.

4. G. Wang, B. Huang, L. Xiao, Z. Ren, H. Chen, D. Wang, H. D. Abruna, J. Lu and L. Zhuang, J Am Chem Soc, 2014, 136, 9643-9649.

5. A. Chen and P. Holt-Hindle, Chemical Reviews, 2010, 110, 3767.

6. M. S. Dresselhaus and I. L. Thomas, Nature, 2001, 414, 332.

7. P. Strasser, Science, 2015, 349, 379-380.

8. M. Winter and R. J. Brodd, Chem. Rev, 2004, 104, 4245.

9. Q. Liu, X. Liu, L. Zheng and J. Shui, Angew Chem Int Ed Engl, 2018, 57, 1204-1208.

10. J. Chen, X. Yuan, F. Lyu, Q. Zhong, H. Hu, Q. Pan and Q. Zhang, Journal of Materials Chemistry A, 2019, 7, 12811286.

11. F. Lyu, Y. Bai, Z. Li, W. Xu, Q. Wang, J. Mao, L. Wang, X. Zhang and Y. Yin, Advanced Functional Materials, 2017, 27, 1702324.

12. C. Chen, Y. Kang, Z. Huo, Z. Zhu, W. Huang, H. L. Xin, J. D. Snyder, D. Li, J. A. Herron and M. Mavrikakis, Science, 2014, 45, 1339-1343.

13. S. Y. Huang, P. Ganesan, S. Park and B. N. Popov, Journal of the American Chemical Society, 2009, 131, 13898-13899.

14. X. X. Wang, S. Hwang, Y. T. Pan, K. Chen, Y. He, S. Karakalos, H. Zhang, J. S. Spendelow, D. Su and G. Wu, Nano Lett, 2018, 18, 4163-4171.

15. Y. J. Wang, N. Zhao, B. Fang, H. Li, X. T. Bi and H. Wang, Chem Rev, 2015, 115, 3433-3467.

16. Y. Nie, L. Li and Z. Wei, Chem Soc Rev, 2015, 44, 2168-2201.

17. J. Pan, C. Chen, Y. Li, L. Wang, L. Tan, G. Li, X. Tang, L. Xiao, J. Lu and L. Zhuang, Energy Environ. Sci., 2014, 7, 354-360.

18. C. Pereira and J. S. K. Reddy, NeuroQuantology, 2018, 16.

19. X. Shi, N. Iqbal, S. S. Kunwar, G. Wahab, H. A. Kasat and A. M. Kannan, International Journal of Hydrogen Energy, 2018, 43, 3520-3526.

20. J. Ying, J. Li, G. Jiang, Z. P. Cano, Z. Ma, C. Zhong, D. Su and Z. Chen, Applied Catalysis B: Environmental, 2018, 225, 496-503.

21. T. H. a. L. G. Genmin Lu *, Catalysis Letters, 1992, 14, 207220.

22. M. Trépanier, A. Tavasoli, A. K. Dalai and N. Abatzoglou, Applied Catalysis A: General, 2009, 353, 193-202.

$23 . \quad$ B. N. Wanjala, R. Loukrakpam, J. Luo, P. N. Njoki, D. Mott, C. J. Zhong, M. H. Shao, L. Protsailo and T. Kawamura, J Phys Chem C, 2010, 114, 17580-17590.
24. S. Chen, Z. Wei, L. Guo, W. Ding, L. Dong, P. Shen, X. Qi and L. Li, Chem Commun (Camb), 2011, 47, 10984-10986.

25. L. Dubau, F. Maillard, M. Chatenet, J. André and E. Rossinot, Electrochimica Acta, 2010, 56, 776-783.

26. J. Liu, M. Jiao, L. Lu, H. M. Barkholtz, Y. Li, Y. Wang, L. Jiang, Z. Wu, D. J. Liu, L. Zhuang, C. Ma, J. Zeng, B. Zhang, D. Su, P. Song, W. Xing, W. Xu, Y. Wang, Z. Jiang and G. Sun, Nat Commun, 2017, 8, 15938.

27. J. Choi, J.-H. Jang, C.-W. Roh, S. Yang, J. Kim, J. Lim, S. J. Yoo and H. Lee, Applied Catalysis B: Environmental, 2018, 225, 530-537.

28. J. Choi, J. Cho, C.-W. Roh, B.-S. Kim, M. S. Choi, H. Jeong, H. C. Ham and H. Lee, Applied Catalysis B: Environmental, 2019, 247, 142-149.

29. C. S. CHEN Wenhui, Acta Phys. -Chim. Sin. , 2019, 35, 517522. 


\section{A neural-network-like catalyst structure for oxygen reduction reaction: carbon nanotubes bridged hollow PtCo alloy nanoparticles in MOF-like matrix for energy technologies}

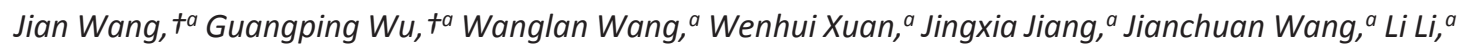
Wen-Feng Lin, ${ }^{b}$ Wei Ding ${ }^{* a}$ and Zidong Wei*a

a Chongqing Key Laboratory of Chemical Process for Clean Energy and Resource Utilization, School of

Chemistry and Chemical Engineering, Chongqing University, Shapingba 174, Chongqing, China

${ }^{b}$ Department of Chemical Engineering, School of AACME, Loughborough University, Loughborough,

Leicestershire, LE11 3TU, U.K.

+ These authors contributed equally.

SUPPORT INFORMATION

Experimental Procedures

Synthesis of PVP-Pt ${ }^{1}$

$2.5 \mathrm{~nm}$ PVP-stabilized Pt nano-particles (NPs) were prepared by refluxing a mixture of PVP (533 mg, $\mathrm{Mw}=30,000)$, methanol $(180 \mathrm{ml})$, and aqueous solution of $\mathrm{H}_{2} \mathrm{PtCl}_{6}(6.0 \mathrm{mM}, 20 \mathrm{ml})$ in a flask $(500 \mathrm{ml})$ for 3 hours under air. Methanol was removed by rotary evaporator. The NPs in the remaining solution were precipitated by acetone and then collected by centrifugation at $6,000 \mathrm{rpm}$ for 5 minutes. The sample was cleaned serval times with methanol and acetone to remove excess free PVP. Finally the obtained Pt NPs were dispersed in methanol (90 ml) to give a Pt content of $0.26 \mathrm{mg} / \mathrm{ml}$ according to the amount of $\mathrm{H}_{2} \mathrm{PtCl}_{6}$.

Synthesis of Pt@ZIF-67

As our thought to simulate the neural network structure, the polyvinyl pyrrolidone (PVP) and dimethyl imidazole $(20 \mathrm{mM} 100 \mathrm{ml})$ capped Pt NPs $(30 \mathrm{ml})$ were used as center species, and connected them together by adding $5 \mathrm{mM} \mathrm{Co}^{2+}$ ions to form Pt@ZIF-67. And then kept at room temperature for 24 hours without stirring, during the formation of ZIF-67, the Pt NPs are uniformly inlayed inside the whole ZIF-67 crystals. The product was collected by centrifugation, washed several times with methanol, and vacuum dried overnight.

Synthesis of PtCo@CNTs-MOF, Co/CNTs-MOF and PtCo/C 
The obtained Pt@ZIF-67 powders were put into quartz tube and then pyrolyzed under $\mathrm{N}_{2}+\mathrm{H}_{2}(9: 1)$ atmosphere with different procedure.

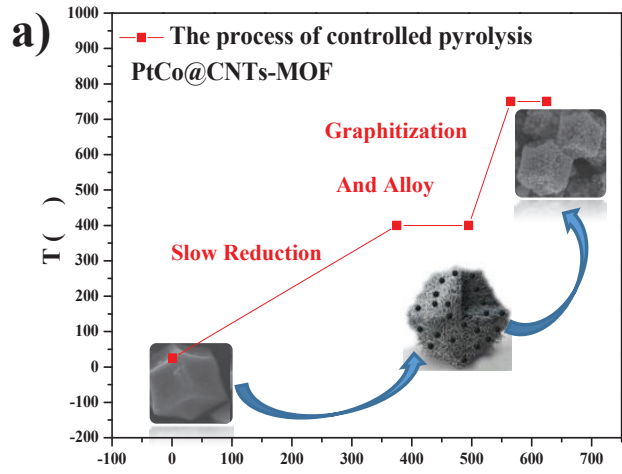

Time (min)

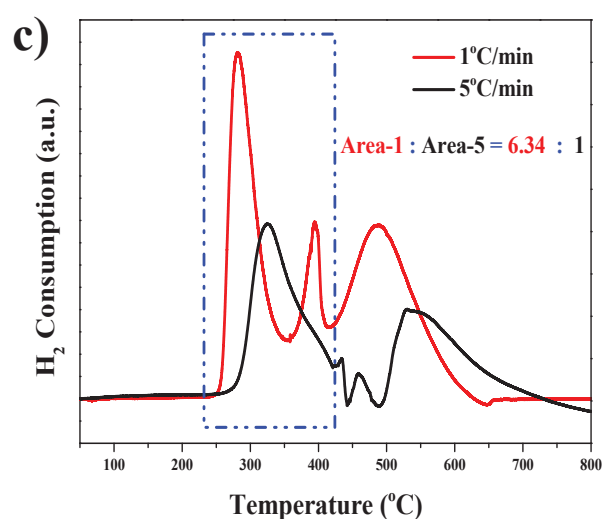

b)

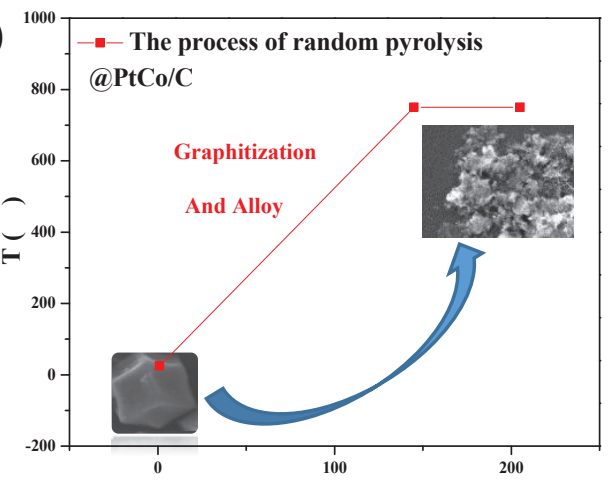

Time (min)

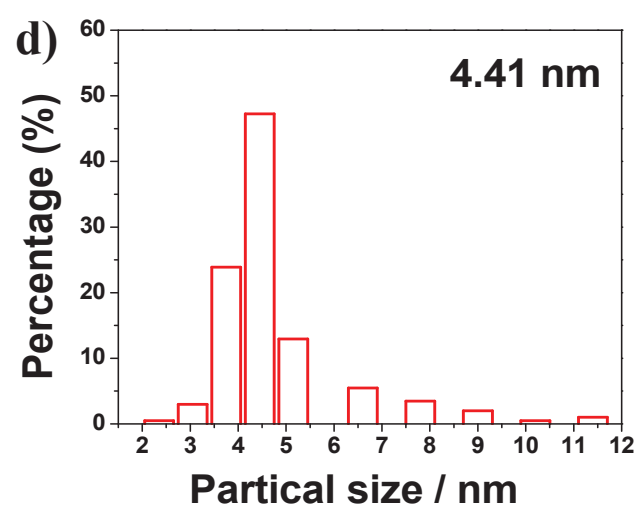

Figure S1. a) The process of controlled pyrolysis for Pt@ZIF-67, b) the process of random pyrolysis for Pt@ZIF-67, c) the $\mathrm{H}_{2}$-TPR profiles of catalysts with different temperature rate, d) the particle size distribution map of PtCo@CNTs-MOF.

Figure S1a. shows the two process of controlled pyrolysis for Pt@ZIF-67, under the first controlled pyrolysis process with a relative low heating up rate $\left(1{ }^{\circ} \mathrm{C} \mathrm{min}-1\right)$, the $\mathrm{Co}^{2+}$ species were firstly reduced by $\mathrm{H}_{2}$, and then reduced Co NPs would catalyze the organic ligands to form carbon nanotubes; under the second controlled pyrolysis process with a relative high heating up rate $\left(5^{\circ} \mathrm{C} \mathrm{min}^{-1}\right)$, the Co NPs would diffuse outward at high temperature, a part of them would form large particles, the other part would diffuse into the encapsulated Pt NPS to form PtCo alloy. At last, the polyhedral morphology could be preserved effectively consist of carbon nanotubes, Co large particles and PtCo alloy. After acid-leached $\left(0.5 \mathrm{M} \mathrm{H}_{2} \mathrm{SO}_{4}\right)$ at $80^{\circ} \mathrm{C}$ for $24 \mathrm{~h}$, the surplus Co NPs would be removed. Finally, the MOF-like neural network structure products consisting of the interconnected carbon nanotubes and hollow Pt ${ }_{3}$ Co NPs could be obtained (PtCo@CNTs-MOF). Similarly process, the Co/CNTs-MOF composites was prepared by one-pot thermal annealing by using ZIF-67 as precursors.

Figure S1b. shows the process of random pyrolysis for Pt@ZIF-67, the $\mathrm{Co}^{2+}$ species would be firstly reduced by organic ligands of ZIF-67 during the random pyrolysis at a high heating up rate of $5{ }^{\circ} \mathrm{C} \mathrm{min}^{-1}$, leading to an uncontrollable collapse in structure and morphology, the part of reduced Co NPs also would aggregate to form large particles, the other would diffuse into the encapsulated Pt NPs to form PtCo alloy. After acid-leached (0.5M $\mathrm{H}_{2} \mathrm{SO}_{4}$ ) at $80^{\circ} \mathrm{C}$ for $24 \mathrm{~h}$, the surplus Co NPs would be removed, and the final products consisting of the $\mathrm{Pt}_{3} \mathrm{Co}$ NPs and ruleless carbon material could be obtained ( $\mathrm{PtCo} / \mathrm{C})$.

\section{Physical Characterization}

Xray diffraction (XRD) patterns were recorded on a XRD6000 using $\mathrm{Cu}$ Kr radiation $(\lambda=1.5418 \AA$ ) at a step rat e of $2^{\circ}$ s-1. Low-resolution transmission electron microscopy (TEM) was carried out on a FEI Tecnai G220S-TWIN instrument operating at $120 \mathrm{kV}$. High-resolution transmission electron microscopy (HRTEM) was carried out on a Zeiss LIBRA 200 FETEM instrument operating at 200 kV. XPS was acquired using a Kratos XSAM 800 spectrometer 
equipped with monochromatic Al X-ray source (AI KR, $1.4866 \mathrm{keV}$ ), the vacuum in the analysis chamber was maintained at $10^{-7} \mathrm{~Pa}$, and the binding energy was calibrated by using $284.5 \mathrm{eV}$ as the $\mathrm{C} 1$ s peak energy.

\section{Electrochemical measurement}

The catalysts were evaluated electrochemically in three-electrode one-compartment cell, in which $0.1 \mathrm{M} \mathrm{HClO}_{4}$ was used as the electrolyte, a saturated $\mathrm{Ag} / \mathrm{AgCl}$ electrode and a carbon rod were used as reference and counter electrodes, respectively.

The electrocatalytic activity of catalysts for oxygen reduction was determined by cyclic voltammetry (CV) at a sweep rate of $50 \mathrm{mv} \mathrm{s}^{-1}$ followed by liner sweep voltammetry (LSV) at a sweep rate of $10 \mathrm{mVs}^{-1}$ with a rotational disk electrode (RDE). The measurements were performed at $25^{\circ} \mathrm{C}$ after purging $\mathrm{O}_{2}$ or $\mathrm{N}_{2}$ for $30 \mathrm{~min}$. RDE measurements were conducted with a varying rotating speed of $1600 \mathrm{rpm}$. A glassy carbon disk of $5 \mathrm{~mm}$ diameter coated with a film of catalyst was used as working electrode. To prepare the working electrode,2mg of PtCo@N-MCF catalyst and a drop of $0.1 \mathrm{wt} \%$ Nafion solution were ultrasonically dispersed in $800 \mu \mathrm{L}$ of a water-ethanol $(1: 1 \mathrm{v} / \mathrm{v})$ mixed solvent to form a homogeneous ink. As a comparison, $2 \mathrm{mg}$ of JM-Pt/C was ultrasonically dispersed in $800 \mu \mathrm{L}$ of EtOH with a drop of a $0.1 \mathrm{wt} \%$ Nafion solution. Then a certain amount of the catalyst ink were loaded onto a RDE, respectively. Finally, the RDE was dried at air temperature. All potentials in this study are given relative to the potential of the reversible hydrogen electrode (RHE).

The electrical double layer capacitance was measured in $0.1 \mathrm{M} \mathrm{HClO}_{4}$ aqueous solution, the scanning potensial range of 0.36-0.46 V versus Reversible hydrogen electrode (RHE) reference at a step of different scan rate $(20,40$, $60,80,100 \mathrm{mV} / \mathrm{s}$ ), the chosed potential range should ensure only non-faradic activity occurs. On the basis of the surface area from BET and the weight of catalyst on the electrode, we could obtain the real catalyst surface area and current density on the electrode. The value of imposed current density is divided by the slope of the lineal chronopotentiogram plot, taking the average value between charge and discharge process at $0.41 \mathrm{~V}$. Finally, the slope is the electrical double layer capacitance.

The chronopotentiometry curves were recorded in $\mathrm{O}_{2}$-purged $0.1 \mathrm{M} \mathrm{HClO}_{4}$ solutions at a different constant current $\left(2 \mathrm{~mA} \mathrm{~cm}^{-2}, 10 \mathrm{~mA} \mathrm{~cm}^{-2}, 30 \mathrm{~mA} \mathrm{~cm}^{-2}, 50 \mathrm{~mA} \mathrm{~cm}^{-2}\right)$, particularly using a self-made working electrode. Firstly, a viscous suspension consisting of catalyst, nafion solution, and ethanol (with mass ratio of nafion to catalyst = $0.35: 1$ ) was pipetted onto the carbon paper to reach Pt loading of $0.025 \mathrm{mg} \mathrm{cm}^{-2}$ (absolute amount of Pt $=0.025$ $\mathrm{mg}$; effective area $=1.0 \mathrm{~cm}^{2}$ ). The catalyst was naturally dried at room temperature and loaded into the ring groove of the working electrode. Specially, the side loaded with catalyst faces outside, allowing that $\mathrm{O}_{2}$ molecules enter into the catalyst layer through carbon paper. When testing, the head of the "rattle-drum" was sealed with Vaseline and totally soaked in the $\mathrm{HClO}_{4}$ solution as working electrode. And the three-electrode systems also include a carbon rob counter electrode and an $\mathrm{Ag} / \mathrm{AgCl}$ (in $3.0 \mathrm{M} \mathrm{KCl}$ ) reference electrode. Flowing rate of $\mathrm{O}_{2}$ is maintained at $10 \mathrm{~mL} / \mathrm{min}$ during the test.

\section{Koutecky-Levich equation ${ }^{2}$}

The slopes of the best linear fit lines were used to calculate the transferred electron number $(n)$ per oxygen molecule in the ORR process on the basis of the Koutecky-Levich equations:

$$
\begin{aligned}
\frac{1}{J} & =\frac{1}{J_{L}}+\frac{1}{J_{K}}=\frac{1}{B w^{1 / 2}}+\frac{1}{J_{K}} \\
B & =0.2 n F C_{0}\left(D_{0}\right)^{2 / 3} u^{-1 / 6}
\end{aligned}
$$

Where $J$ is the measured current density, $J_{K}$ and $J_{L}$ are the kinetic- and diffusion-limiting current densities, $\omega$ is the electrode rotating speed in $\mathrm{rpm}, \mathrm{n}$ is the electron transfer number in oxygen reduction, $F$ is the Faraday constant $\left(F=96485 \mathrm{C} \mathrm{mol}^{-1}\right), C_{0}$ is the bulk concentration of $O_{2}\left(C_{0}=1.13 \times 10^{-6} \mathrm{~mol} \mathrm{~cm}^{-3}\right), D_{0}$ is the diffusion coefficient of $\mathrm{O}_{2}\left(1.8 \times 10^{-5} \mathrm{~cm}^{2} \mathrm{~s}^{-1}\right), v$ is the kinematic viscosity of the electrolyte $\left(0.01 \mathrm{~cm}^{2} \mathrm{~s}^{-1}\right)$, The constant 0.2 is adopted when the rotating speed is in rpm

The specific kinetic current densities $\left(J_{k}\right)$ associated with the intrinsic activity of the catalysts can be obtained by the following relation:

$$
J_{k}=\frac{J_{d}^{*} J}{J_{d}-J}
$$


Where $J$ is the measured current density, $J_{k}$ is the kinetic current density; $J_{d}$ is the diffusion-limited current density, respectively.

\section{Single Fuel cell testing.}

The PtCo@CNTs-MOF catalyst "ink" was prepared by ultrasonically mixing the catalyst powder with 5wt\% Nafion solution (DuPont) and anhydrous alcohol for approximately $15 \mathrm{~min}$. The Nafion content in the dry catalyst layer was $33 \mathrm{wt} \%$. The gas diffusion layer heated at $80^{\circ} \mathrm{C}$ for 3 hours under vacuum or not. The weight difference was measured and used to calculate the loading of the catalysts. The Pt loading was $0.06 \mathrm{mg} \mathrm{cm}^{-2}$ when the PtCo@CNTs-MOF catalyst used as cathode, respectively. After spray deposition process, let the gas-diffusion electrode dry under vacuum condition or ordinary pressure. A suspension consisting of $60 \mathrm{wt} \% \mathrm{PtRu} / \mathrm{C}$ catalysts (Johnson-Matthey In. UK), 5 wt\% Nafion solution (DuPont), and isopropyl alcohol was used to prepare the opposite catalyst layer. The Pt loading was controlled at $0.04 \mathrm{mg} \mathrm{cm}^{-2}$ or $0.06 \mathrm{mg} \mathrm{cm}^{-2}$ on the anodic side. The MEA was prepared by hot-pressing the cathode, Nafion 212 membrane (DuPont, $50 \mu \mathrm{m}$ ), and the anode at 135으 and $5 \mathrm{MPa}$ for 150s. The Nafion HP membrane (DuPont) was pretreated with 3 vol. $\% \mathrm{H}_{2} \mathrm{O}_{2}$ and $0.5 \mathrm{M} \mathrm{H}_{2} \mathrm{SO}_{4}$ for $1 \mathrm{~h}$ to remove impurities. The membrane was then washed several times with hot ultrapure water. Pure hydrogen and oxygen/air were supplied to the anode and cathode at a flow rate of 150 and $200 \mathrm{~mL} \mathrm{~min}^{-1}$, respectively.
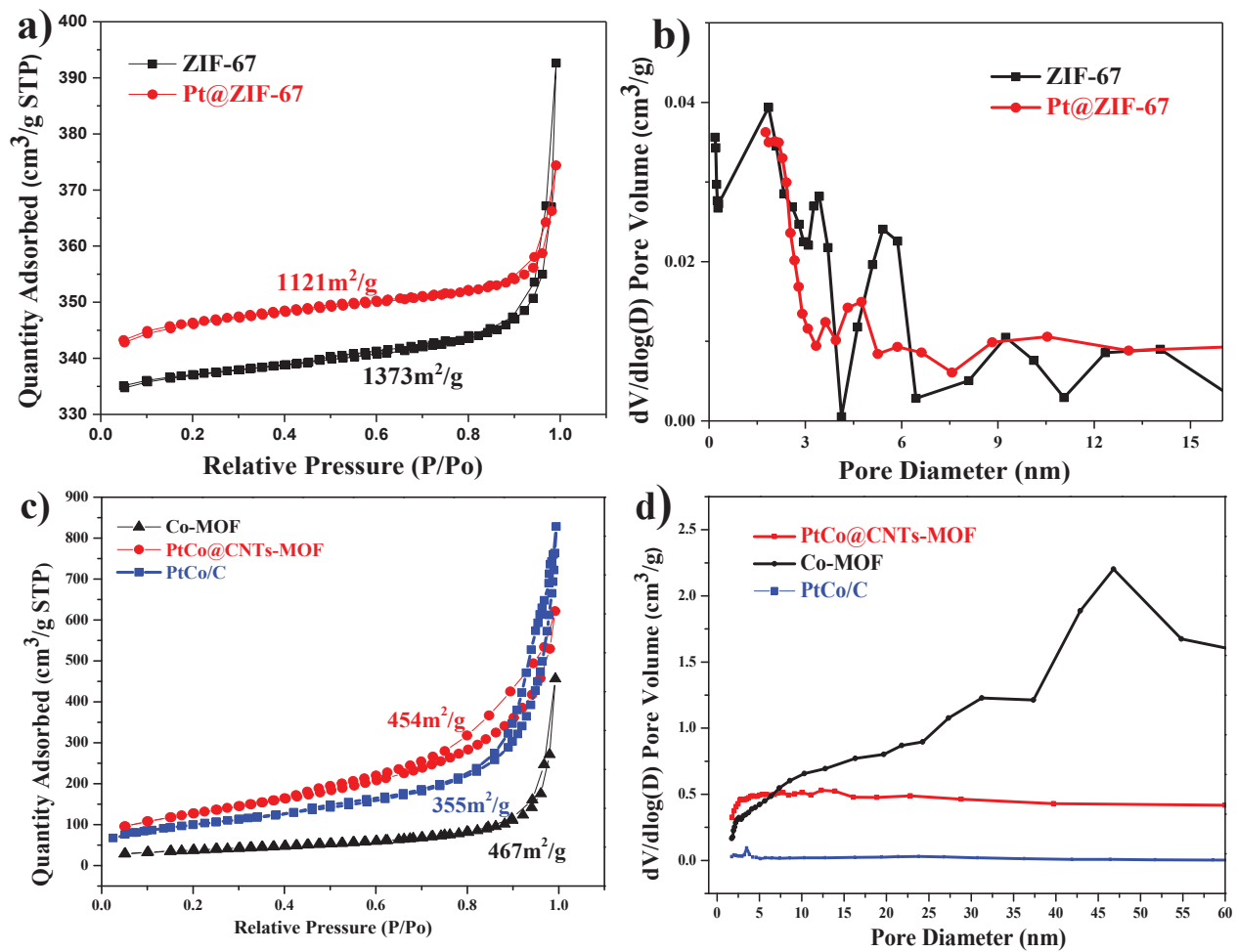

Fig S2. Nitrogen adsorption and desorption isotherms of a) ZIF-67, Pt@ZIF-67 and c) PtCo@CNTs-MOF, Co-MOF,

b) and d) the pore size distribution of ZIF-67, Pt@ZIF-67 PtCo@CNTs-MOF and Co-MOF composites, respectively. 

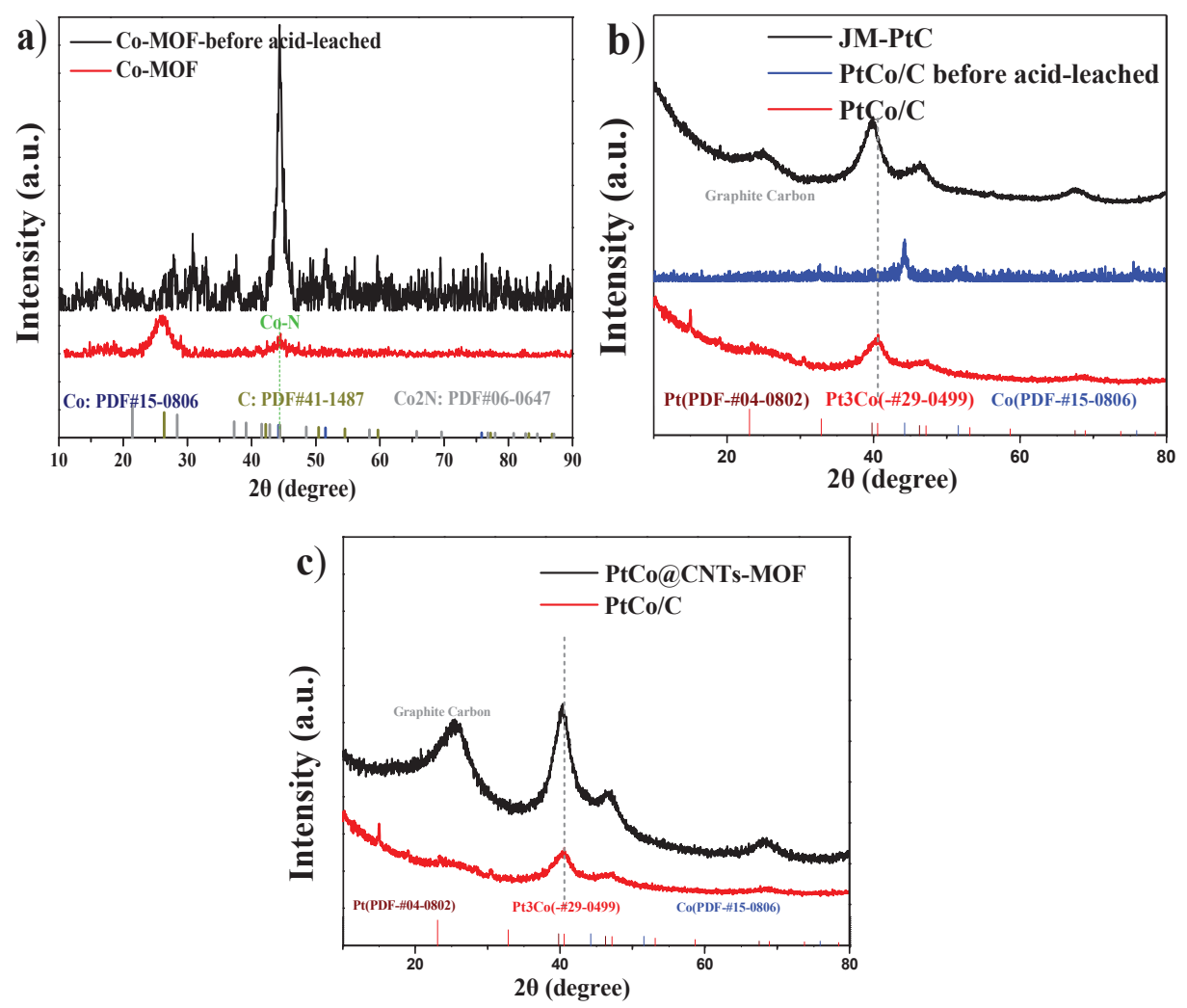

Fig S3. The XRD of Co-MOF (a) and PtCo/C in random pyrolysis (b) before and after acid-leaching treatment, $\mathrm{c}$ ) XRD pattern for the PtCo@CNTs-MOF catalyst in comparison to that of PtCo/C. The XRD patterns show a relatively strong diffraction peak around $25^{\circ}$ for the PtCo@CNTs-MOF catalyst obtained at the low heating rate pyrolysis $\left(1^{\circ} \mathrm{C} \mathrm{min}^{-1}\right)$ but a weak peak for the $\mathrm{PtCo} / \mathrm{C}$, indicating a much higher graphitization degree for PtCo@CNTs-MOF than that for PtCo/C. Besides, the diffraction peaks at $40^{\circ}$ and $47^{\circ}$ attributing to intermetallic $\mathrm{Pt}_{3} \mathrm{Co}$ (111) and (200) were also more sharpened for PtCo@CNTs-MOF than those for PtCo/C, demonstrating a relatively higher crystallization degree obtained at the low heating rate in PtCo@CNTs-MOF.
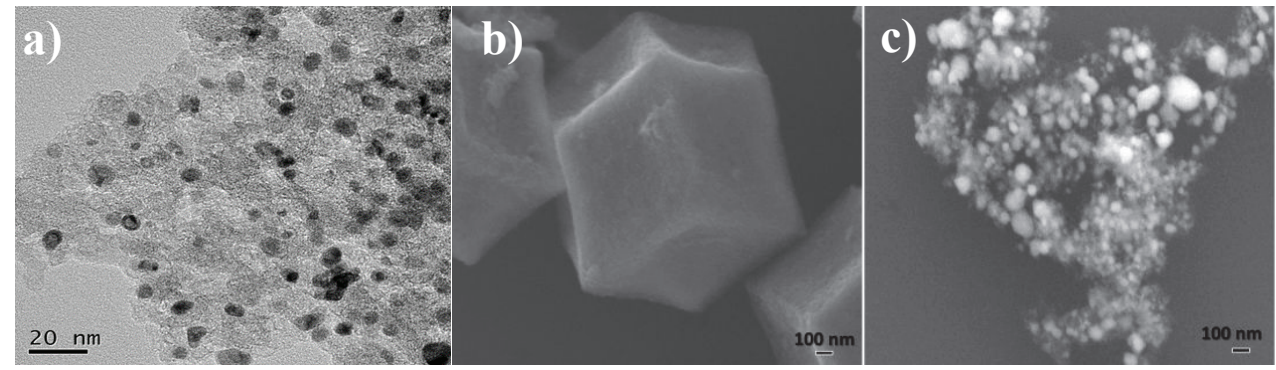

Fig S4. a) The TEM of PtCo/C after acid-leaching treatment, b) the SEM of PtCo@CNTs-MOF, c) the SEM of $\mathrm{PtCo} / \mathrm{C}$. According to the SEM and TEM images, the PtCo@CNTs-MOF catalyst exhibited a porous MOF-like structure, which consisted of interconnected CNTs with a diameter of $8 \mathrm{~nm}$ and hollow $\mathrm{Pt}_{3} \mathrm{Co} \mathrm{NPs}_{\text {with a wall }}$ thickness of $1.5 \mathrm{~nm}$ (figure $2 \mathrm{f}-\mathrm{i}$ ). However, for $\mathrm{PtCo} / \mathrm{C}$, the original polyhedral MOF morphology was completely destroyed during the pyrolysis at heating rate of $5{ }^{\circ} \mathrm{C} \mathrm{min}^{-1}$; and the BET surface area decreased from $454 \mathrm{~m}^{2} \mathrm{~g}^{-1}$ for PtCo@CNTs-MOF to $355 \mathrm{~m}^{2} \mathrm{~g}^{-1}$ for PtCo/C, when the heat rate increased from 1 to ${ }^{\circ} \mathrm{C} \mathrm{min}^{-1}$. The collapsed 
structure and decreased BET surface area in PtCo/C may bring relatively higher resistance for mass transfer during the catalysis.

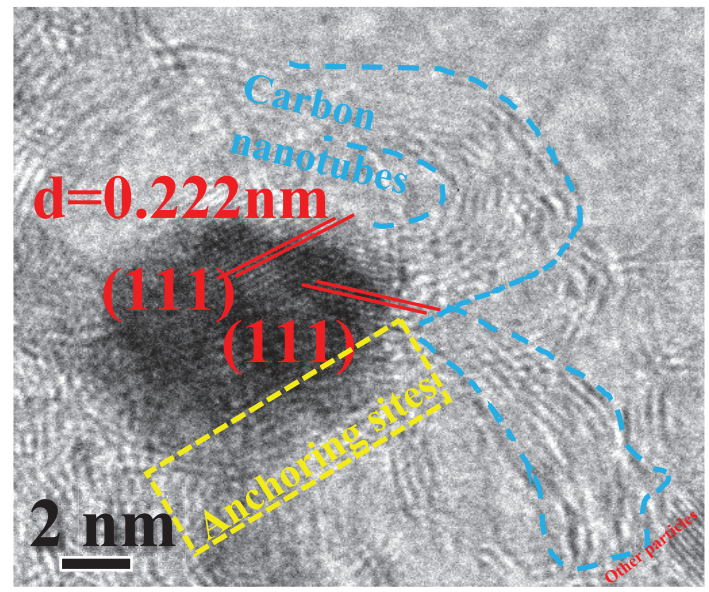

Fig S5. The TEM of PtCo@CNTs-MOF after acid- leaching treatment.

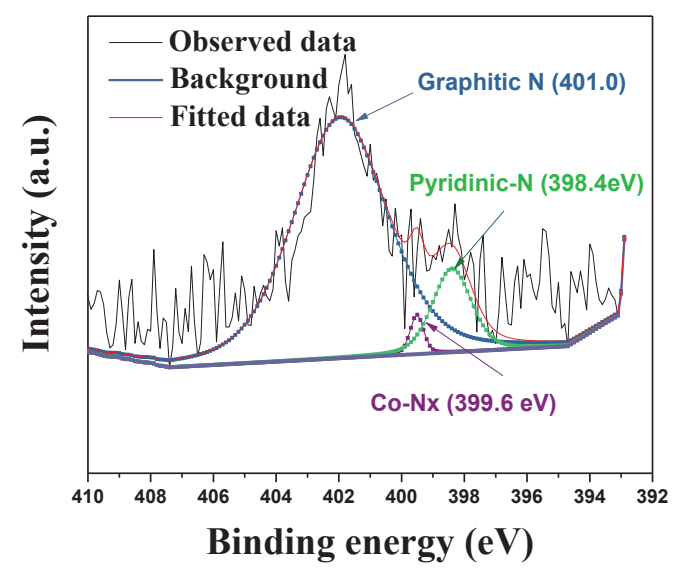

Fig S6. The XPS of PtCo@CNTs-MOF for N elements. 

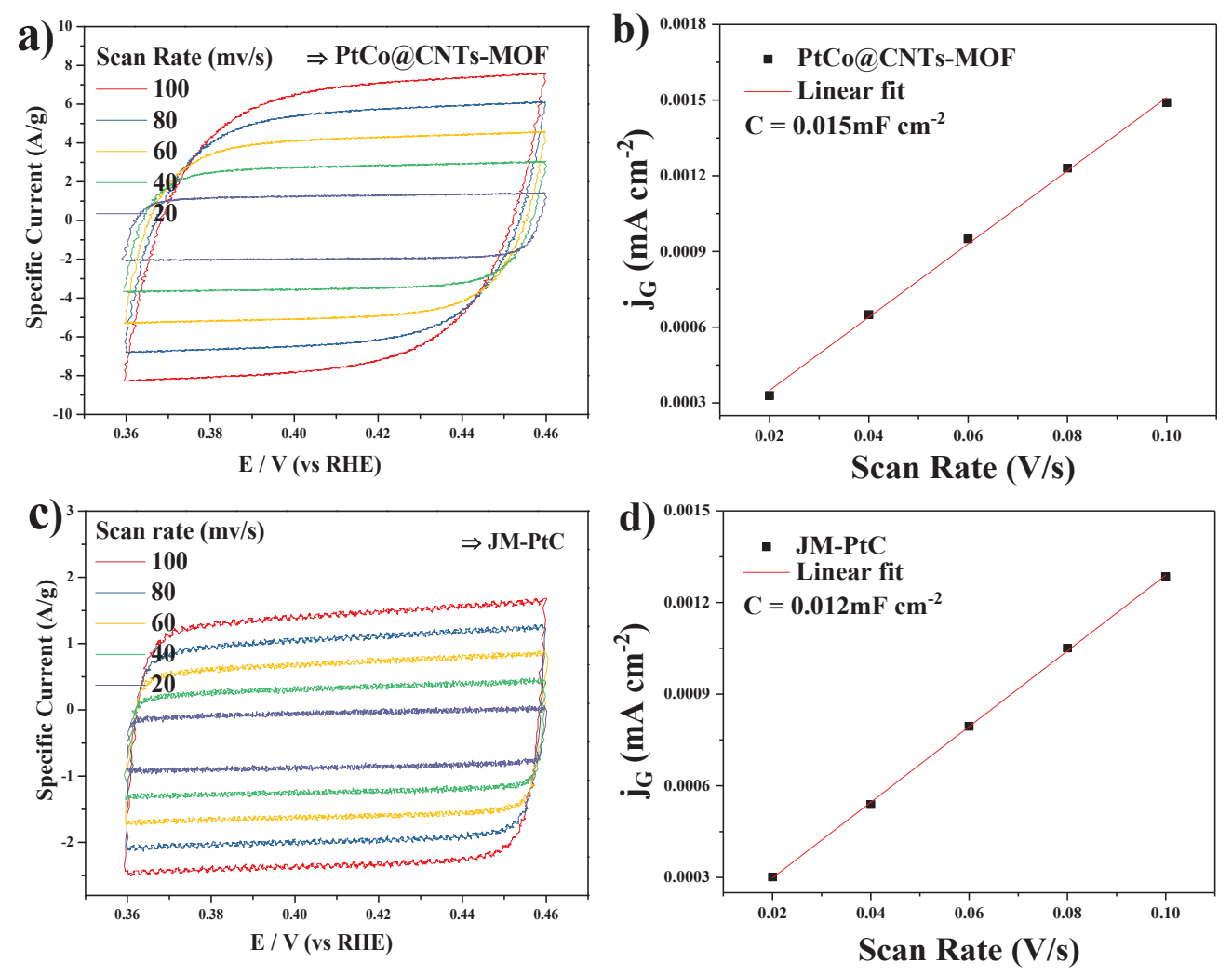

Fig S7. a), c) Cyclic voltammograms within the range of no faradaic reactions. b), d) Variation of double layer charging currents at $+0.41 \mathrm{~V}$ as a function of scan rate, respectively
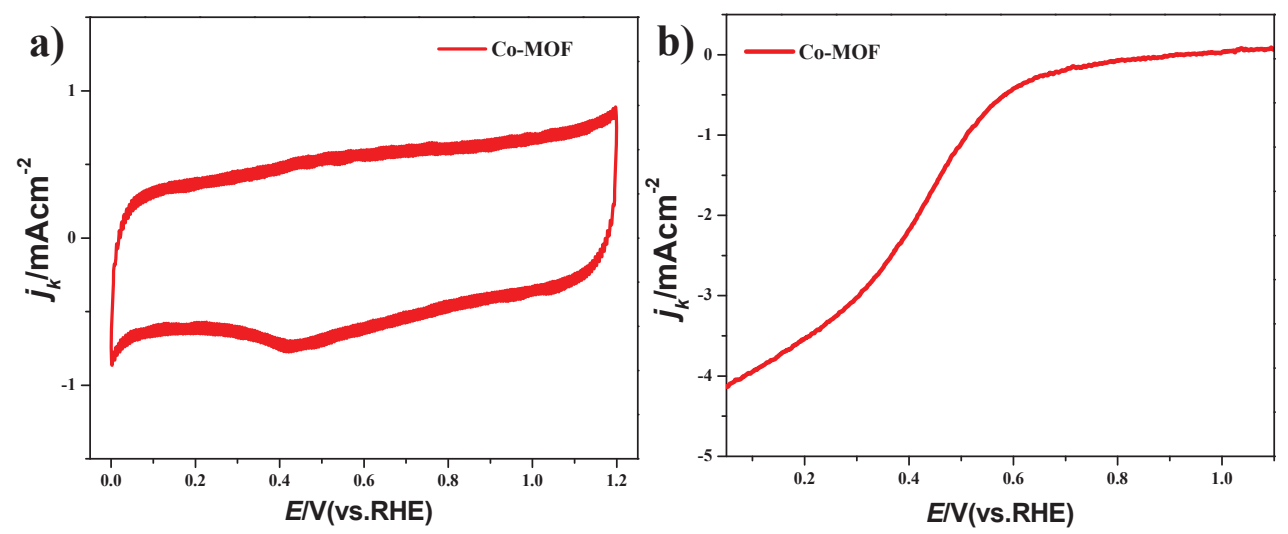

Fig S8. The CV and LSV curves of Co-MOF in $0.1 \mathrm{M} \mathrm{HClO}_{4}$ solution. 

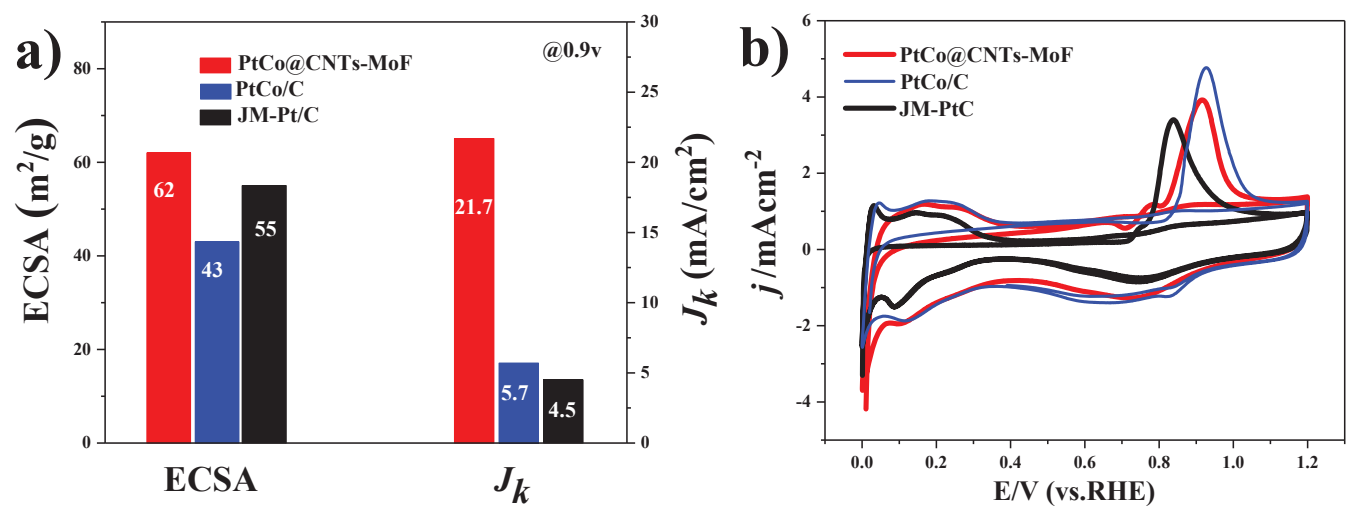

Fig S9. a) The ECSA and $\mathrm{J}_{\mathrm{k}}$ of PtCo@CNTs-MOF, PtCo/C and JM-Pt/C, b) the CO-stripping curves of PtCo@CNTs$\mathrm{MOF}, \mathrm{PtCo} / \mathrm{C}$ and $\mathrm{JM}-\mathrm{Pt} / \mathrm{C}$ were recorded at room temperature in CO-saturated $0.1 \mathrm{M} \mathrm{HClO}_{4}$ solution at scan rate of $50 \mathrm{mVs}^{-1}$.

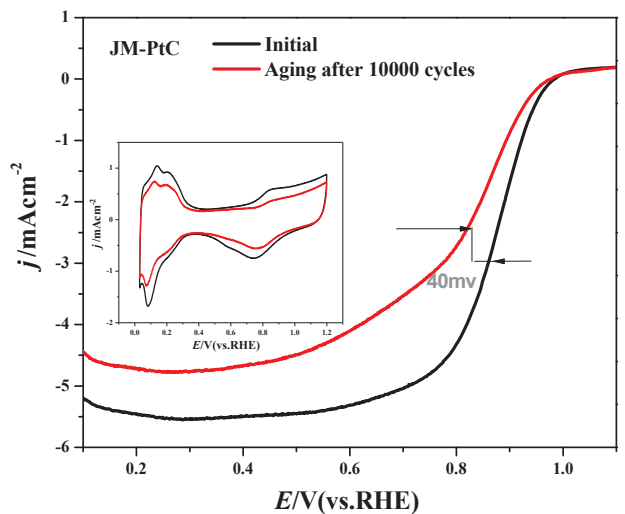

Fig S10. The CV and LSV curves of JM-Pt/C-20 wt\% in $\mathrm{O}_{2}$-saturated $0.1 \mathrm{M} \mathrm{HClO}_{4}$ solution. The $\mathrm{CV}$ was recorded at a $50 \mathrm{mV} \mathrm{s}^{-1}$ scan rate before after aged.
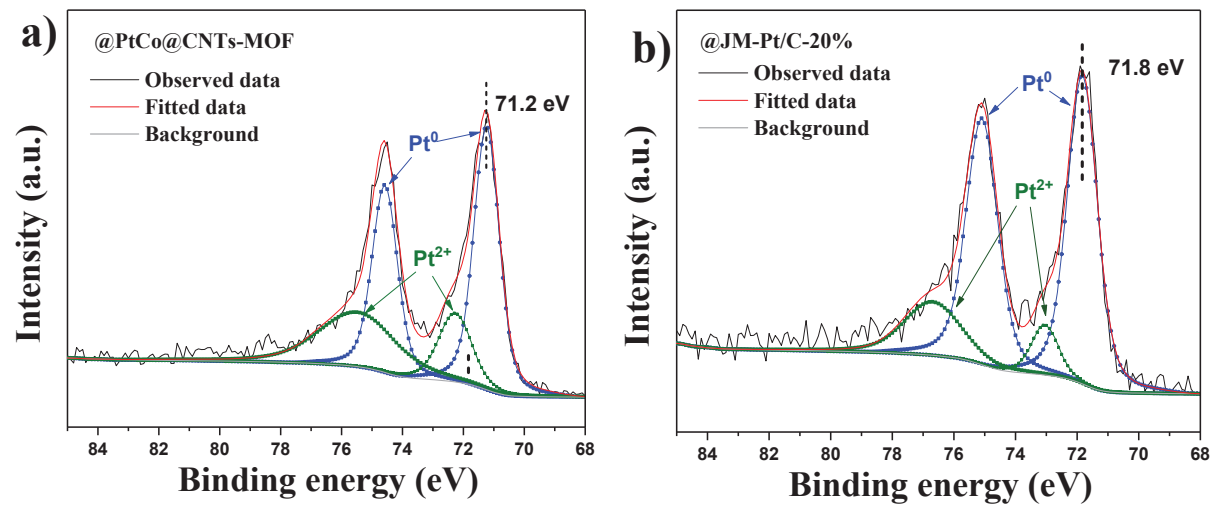

Fig S11. The XPS of PtCo@CNTs-MOF and JM-Pt/C-20\% for Pt elements. 
Table S1. The BET parameters of different samples.

\begin{tabular}{cccc}
\hline Samples & $\begin{array}{c}\text { Surface area } \\
\left(\mathrm{m}^{2} / \mathrm{g}\right)\end{array}$ & $\begin{array}{c}\text { micropore volume } \\
\left(\mathrm{cm}^{3} / \mathrm{g}\right)\end{array}$ & $\begin{array}{c}\text { Average pore diameter } \\
(\mathrm{nm})\end{array}$ \\
ZIF-67 & 1372.70 & 0.66 & 14.84 \\
Pt@ZIF-67 & 1121.03 & 0.52 & 9.56 \\
Co-MOF-before acid-leached & 133.90 & 0.0073 & 21.51 \\
PtCo@CNTs-MOF-before acid-leached & 146.67 & 0.0030 & 9.60 \\
Co-MOF & & & 21.24 \\
PtCo/C & 467.29 & 0.0070 & 14.13 \\
PtCo@CNTs-MOF & 354.67 & 0.0080 & 8.28 \\
\hline
\end{tabular}

\section{Uncategorized References}

1. Teranishi, T.; Hosoe, M.; Tanaka, T.; Miyake, M., Size control of monodispersed Pt nanoparticles and their 2D organization by electrophoretic deposition. J Phys Chem B 1999, 103 (19), 3818-3827.

2. Chen, W.; Chen, S. W., Oxygen Electroreduction Catalyzed by Gold Nanoclusters: Strong Core Size Effects. Angew Chem Int Edit 2009, 48 (24), 4386-4389. 